\title{
BMJ
}

\section{Outcomes of conduct problems in adolescence: 40 year follow-up of national cohort}

\author{
Ian Colman, assistant professor, ${ }^{1}$ Joseph Murray, postdoctoral fellow, ${ }^{2}$ Rosemary A Abbott, research \\ associate, ${ }^{3}$ Barbara Maughan, professor, ${ }^{4}$ Diana Kuh, professor, director, ${ }^{5}$ Tim J Croudace, senior lecturer, ${ }^{3}$ \\ Peter B Jones, psychiatrist, professor, head ${ }^{3}$
}

\begin{abstract}
${ }^{1}$ School of Public Health, University of Alberta, 13-130D

Clinical Sciences Building, Edmonton, AB, Canada T6G 2G3

${ }^{2}$ Institute of Criminology, University of Cambridge, Cambridge

${ }^{3}$ Department of Psychiatry, University of Cambridge, Cambridge

${ }^{4}$ MRC Social, Genetic and Developmental Psychiatry Centre, King's College London Institute of Psychiatry, London

${ }^{5}$ Medical Research Council National Survey of Health and Development, Department of Epidemiology and Public Health, University College London Medical School, London
\end{abstract}

Correspondence to: I Colman ian.colman@ualberta.ca

Cite this as: BMJ 2009;338:a2981 doi:10.1136/bmj.a2981

\section{ABSTRACT}

Objective To describe long term outcomes associated with externalising behaviour in adolescence, defined in this study as conduct problems reported by a teacher, in a population based sample.

Design Longitudinal study from age 13-53.

Setting The Medical Research Council National Survey of Health and Development (the British 1946 birth cohort).

Participants 3652 survey members assessed by their teachers for symptoms of externalising behaviour at age 13 and 15.

Main outcome measures Mental disorder, alcohol abuse, relationship difficulties, highest level of education, social class, unemployment, and financial difficulties at ages 36-53.

Results 348 adolescents were identified with severe externalising behaviour, 1051 with mild externalising behaviour, and 2253 with no externalising behaviour. All negative outcomes measured in adulthood were more common in those with severe or mild externalising behaviour in adolescence, as rated by teachers, compared with those with no externalising behaviour. Adolescents with severe externalising behaviour were more likely to leave school without any qualifications (65.2\%; adjusted odds ratio $4.0,95 \%$ confidence interval 2.9 to 5.5 ), as were those with mild externalising behaviour (52.2\%; 2.3 , 1.9 to 2.8 ), compared with those with no externalising behaviour (30.8\%). On a composite measure of global adversity throughout adulthood that included mental health, family life and relationships, and educational and economic problems, those with severe externalising behaviour scored significantly higher $(40.1 \%$ in top quarter), as did those with mild externalising behaviour (28.3\%), compared with those with no externalising behaviour (17.0\%).

Conclusions Adolescents who exhibit externalising behaviour experience multiple social and health impairments that adversely affect them, their families, and society throughout adult life.

\section{INTRODUCTION}

Behavioural and externalising disorders affect about $7 \%$ of those aged $9-15 .{ }^{12}$ Conduct disorder, a severe form of externalising behaviour, has been highlighted as one of the most common psychiatric disorders among adolescents. ${ }^{12}$ Conduct disorder causes severe functional impairment ${ }^{3}$ and often presents with other disorders such as depression and anxiety. ${ }^{13}$ Furthermore, evidence suggests that the prevalence of adolescent conduct problems has been increasing over the past 30 years. ${ }^{4}$

More than 40 years ago, in her seminal book Deviant Children Grown Up, Robins showed that adolescents with conduct problems have a poor long term prognosis in adult life. ${ }^{5}$ Individuals who had been treated for a behavioural disorder between 1922 and 1932 were not only more likely than control subjects to engage in criminal behaviour in adulthood but were also more likely to be divorced or separated, be in a lower social class, be unemployed or have financial difficulties, be more likely to abuse alcohol, and be more likely to be treated for psychiatric illness. ${ }^{5}$

Subsequently, many prospective studies have replicated and extended these findings. Conduct problems in adolescence are associated with leaving school earlier or with fewer qualifications, ${ }^{6-8}$ becoming a parent at a young age, ${ }^{7-9}$ unemployment, ${ }^{6-10}$ divorce or separation, ${ }^{9}$ substance abuse, ${ }^{7-14}$ other psychiatric disorders including depression and anxiety, ${ }^{7811-16}$ and suicidal behaviour. ${ }^{71}$ These individuals create a considerable economic burden to society, not only in terms of crime, but also with respect to additional needs in the areas of education, health, and welfare. ${ }^{17}$ Conduct problems are more common in adolescent males, ${ }^{1618}$ and evidence from one study suggests that women with conduct problems in adolescence experience internalising and relationship problems in adulthood, while men experience externalising and economic problems. ${ }^{18}$

While these studies paint a comprehensively poor picture of adult life for adolescents with conduct problems, the evidence is largely based on clinical or high risk samples from disadvantaged populations, ${ }^{9} 101417$ which include more severe cases. This bias can be overcome by studying externalising behaviour in population based samples that offer insights into milder forms of conduct problems and the full range of societal impacts. Many population based cohort studies have 
prospectively followed adolescents with conduct problems into adulthood, ${ }^{6-811-13}$ but to date they have been able to report only on outcomes in early adulthood up to age 32. In addition, these studies tended to focus on those with severe conduct problems and not on individuals who engage in externalising behaviour that might not meet diagnostic criteria for conduct disorder. Evidence from New Zealand, however, suggests a continuum, with increasing externalising behaviour leading to increased likelihood of poor outcomes in adulthood. ${ }^{67}$

We examined the adult lives of adolescents with mild and severe externalising behaviour as reported by their teachers, using repeat measures of mental health, social, and economic outcomes at ages 36-53 in a national birth cohort. We also identified sex specific differences in the outcomes of adolescent externalising behaviour.

\section{METHODS}

Sample

Our sample comprised the Medical Research Council National Survey of Health and Development (NSHD). The survey originally included every child born in England, Scotland, or Wales during one week in March 1946. A stratified sample of 5362 was selected from all singleton births to married women by taking a random one in four of all births to wives of manual workers and all births to wives of non-manual and agricultural workers. That sample has been prospectively studied on 17 occasions up to age 26 , and additionally at ages 31, 36, 43, and 53. ${ }^{19}$ Comparisons with census data show that the remaining cohort is broadly representative of all native born adults currently living in England, Scotland, and Wales. ${ }^{19}$

We report on 3652 survey members whose behaviour was assessed at ages 13 and 15 .

\section{Externalising behaviour in adolescence}

Teachers assessed externalising behaviour using questionnaires that were forerunners of the Rutter child measures. Individual items were rated by teachers as more frequent, the same as, or less frequent than other children in the class. These questionnaires have previously been subjected to factor analysis, with one factor defining severity of externalising psychopathology. ${ }^{20}$ Confirmatory factor analysis for categorical data (normal ogive item response models) with MPlus Version 3.01 defined a similar seven item factor that included disobedience, lying, lack of punctuality, restlessness, truancy, day dreaming in class, and poor response to discipline.

We summed the seven items to create a scale score (7-21), with higher scores representing more externalising behaviour. Cronbach's $\alpha$ was calculated for the scale at ages 13 and 15 , with $\alpha$ of 0.69 and 0.75 , respectively, indicating the scale was reliable. Adolescents were grouped into three categories according to this scale: those who scored below the 75 th centile at 13 and 15 were considered to have no externalising behaviour, those who scored above the 93rd centile at either age 13 or 15 were considered to have severe externalising behaviour, and all others were considered to have mild externalising behaviour. We chose the $93 \mathrm{rd}$ centile to replicate the $7 \%$ prevalence of conduct disorder reported among adolescents of a similar age. ${ }^{12}$ Though few data were available on externalising behaviour earlier in childhood, children identified by their teachers as engaging in externalising behaviour at ages 13 and 15 were more likely to have been labelled "aggressive" by their teacher at the age of 10 (odds ratio $2.2,95 \%$ confidence interval 1.3 to 3.7 for mild externalising behaviour; $10.0,6.0$ to 16.6 for severe externalising behaviour) and more likely to have been labelled "aggressive" by their mother at the same age $(1.8,1.2$ to 2.7 , and $3.2,2.0$ to 5.2 , respectively).

\section{Outcomes}

Mental health in adulthood-The survey measured mental health in adulthood using longitudinal latent classes, capturing experience of common symptoms of depression and anxiety at ages 36,43 , and $53 .{ }^{21}$ Survey members were grouped into those who had no symptoms, mild-moderate symptoms, or severe symptoms in adulthood. In addition, survey members were asked if they had "ever suffered from nervous trouble" at ages 36 and 43. Finally, survey members were considered to be abusing alcohol at ages 43 and 53 if they responded positively to two or more items on the CAGE screening questionnaire. ${ }^{22}$

Family life in adulthood - Survey members reported on their marital status at ages 36,43 , and 53 and also on their number of previous marriages, and were grouped into those with a single continuing marriage, those who had divorced at least once, and those who remained single. Survey members reported the age of their first child and were grouped into those who had a child during the teenage years and those who did not. At ages 36 and 43 they were asked if they were "happy with their family life. At ages 36, 43, and 53 survey members reported whether they had relationship difficulties with their spouse, children, or friends.

Employment and educational outcomes in adulthoodSocial class of the survey members in adulthood was based on the registrar general's classification of social class according to the current or last occupation ${ }^{23}$; members were grouped into manual or non-manual social classes. Survey members also reported their employment status and whether they had financial difficulties at ages 36, 43, and 53. Highest level of education was recorded according to examination reports and self report at age 26 . Survey members were grouped into those with no qualifications (that is, left school before completion) and those with some qualifications. $^{24}$

Global life adversity -We created a composite variable to capture global adversity in adult life. We followed methods used by others to measure "life success" 10 or "adult adjustment problems" by adding one point for each negative outcome in adulthood: symptoms of depression or anxiety, self reported history of nervous trouble, alcohol abuse, divorce, 
Table 1|Comparison of baseline characteristics of those with or without externalising behaviour (mild and severe) in adolescence. Figures are means (SD) unless stated otherwise

\begin{tabular}{lcccc} 
& None $(\mathrm{n}=\mathbf{2 2 5 3 )}$ & Mild $(\mathrm{n}=\mathbf{1 0 5 1 )}$ & Severe $(\mathrm{n}=\mathbf{3 4 8})$ & P value* $^{*}$ \\
Sex $(\%$ male) & 48.9 & 54.8 & 62.6 & $<0.001$ \\
\hline Father's social class (\% manual) & 53.2 & 63.9 & 73.5 & $<0.001$ \\
\hline Cognitive ability at age 8 & $23.0(6.9)$ & $20.4(7.0)$ & $19.0(7.5)$ & $<0.01$ \\
\hline Depression/anxiety: & & & \\
\hline At age 13 & $21.2(2.0)$ & $21.4(2.2)$ & $21.4(2.7)$ & $<0.001$ \\
\hline At age 15 & $21.3(2.0)$ & $21.6(2.4)$ & $22.1(3.0)$ & $<0.001$ \\
\hline
\end{tabular}

*For difference between three groups.
Within each group, we compared individuals with complete data over follow-up with those with incomplete data using similar tests to assess bias.

Outcomes in adulthood are presented across the three groups. In cases where there were repeated reports on the same outcome, we combined these multiple reports into an ordinal scale. In cases where outcomes were rare, we collapsed categories to ensure adequate statistical power.

We compared adolescents with or without externalising behaviour using regression models with the externalising group defined as a three level categorical variable. We used logistic regression for binary outcomes and ordinal regression for ordinal outcomes. (The proportional odds assumption held for all ordinal regression models.) For marital history, we use multinomial regression because of three non-ordered categories (married, divorced, single). Odds ratios and $95 \%$ confidence intervals were additionally adjusted in the logistic model for sex, father's social class, cognitive ability, and depressive and anxious symptoms at age 13 and 15 as these factors differed between the externalising groups and might confound the relation between adolescent externalising behaviour and adult outcomes. Finally, we studied sex specific outcomes for all outcomes and investigated interactions between sex and externalising behaviour in the regression models for all outcomes.

All analyses were performed with Stata 10.0. were permitted to re-enter the study after missing an outcome assessment in adulthood as long as they had the original assessment in adolescence. Of the sample of 3652 , there were $2582(70.7 \%)$ respondents at age 36 , $2510(68.7 \%)$ at age 43, and $2297(62.9 \%)$ at age 53 .

\section{Statistical methods}

We compared the three groups (no externalising behaviour, mild externalising behaviour, severe externalising behaviour, as rated by teacher) on several baseline and early childhood measures using $\chi^{2}$ tests for dichotomous outcomes and the Kruskal-Wallis test for continuous outcomes. These measures included sex, father's social class (manual $v$ non-manual), cognitive ability at age 8 (a previously used composite measure of reading, vocabulary, and arithmetic tests), ${ }^{24}$ and symptoms of depression and anxiety at age 13 and 15 (a previously used composite measure of teacher reported symptoms). ${ }^{25}$

\section{RESULTS}

In the sample, $348(9.5 \%)$ adolescents had severe externalising behaviour, $1051(28.8 \%)$ had mild externalising behaviour, and $2253(61.7 \%)$ had no externalising behaviour. Table 1 shows descriptive characteristics of the three groups. Adolescents with externalising behaviour were more likely to be boys, have a father from a manual social class, have lower cognitive ability, and were slightly more likely to report depressive and anxious symptoms. In all cases, characteristics of those with mild externalising behaviour fell between those with severe externalising behaviour and those with no externalising behaviour.

Adolescents with externalising behaviour were less likely to provide complete data throughout the followup (complete data available for $65.5 \%$ of those with no

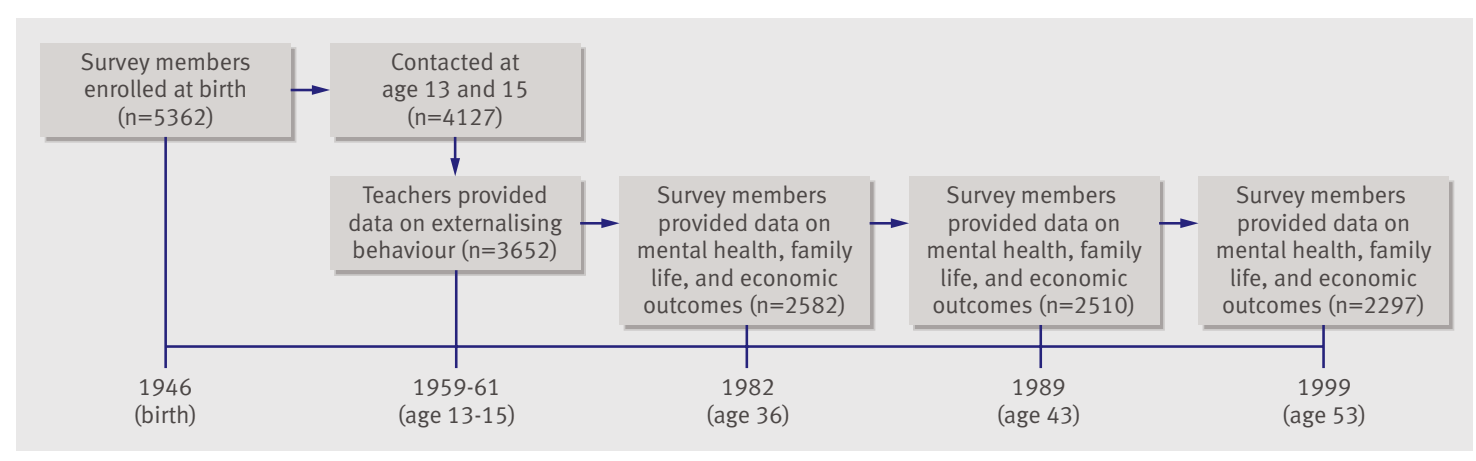

Flow diagram of sample included in analyses over time 
Table 2 |Comparison of those with missing data during follow-up versus those with complete data throughout, according to level of adolescent externalising behaviour (none, mild, severe). Figures are means (SD) unless stated otherwise

\begin{tabular}{|c|c|c|c|c|c|c|}
\hline & \multicolumn{2}{|c|}{ None } & \multicolumn{2}{|c|}{ Mild } & \multicolumn{2}{|c|}{ Severe } \\
\hline & $\begin{array}{c}\text { Complete data } \\
(n=1476)\end{array}$ & $\begin{array}{l}\text { Any missing data } \\
\qquad(\mathrm{n}=777)\end{array}$ & $\begin{array}{l}\text { Complete data } \\
(n=629)\end{array}$ & $\begin{array}{l}\text { Any missing data } \\
(n=422)\end{array}$ & $\begin{array}{l}\text { Complete data } \\
(n=192)\end{array}$ & $\begin{array}{l}\text { Any missing data } \\
\qquad(\mathrm{n}=156)\end{array}$ \\
\hline Sex (\% male) & 46.5 & $53.3^{\star \star}$ & 52.0 & $59.0^{\star}$ & 57.8 & $68.6^{*}$ \\
\hline Father's social class (\% manual) & 52.2 & 55.1 & 62.8 & 65.5 & 69.3 & 78.6 \\
\hline Cognitive ability at age 8 & $23.2(6.8)$ & $22.6(7.2)^{\star}$ & $20.8(6.7)$ & $19.9(7.3)^{\star}$ & $20.4(7.5)$ & $17.4(7.1)^{\star \star \star}$ \\
\hline \multicolumn{7}{|l|}{ Depression/anxiety: } \\
\hline At age 13 & $21.1(1.9)$ & $21.3(2.1)$ & $21.3(2.1)$ & $21.7(2.3)^{\star \star}$ & $21.2(2.7)$ & $21.6(2.6)$ \\
\hline At age 15 & $21.3(2.0)$ & $21.4(2.1)$ & $21.4(2.2)$ & $21.9(2.6)^{\star \star}$ & $22.0(2.8)$ & $22.2(3.3)$ \\
\hline \multicolumn{7}{|l|}{ Externalising: } \\
\hline At age 13 & $7.7(0.8)$ & $7.8(0.8)$ & $9.7(1.5)$ & $9.7(1.4)$ & $11.8(2.4)$ & $12.0(2.6)$ \\
\hline At age 15 & $7.7(0.8)$ & $7.8(0.8)^{\star}$ & $9.7(1.5)$ & $9.9(1.5)^{\star}$ & $12.7(2.4)$ & $13.1(2.5)$ \\
\hline
\end{tabular}

externalising behaviour, $59.9 \%$ with mild externalising behaviour, $55.2 \%$ with severe externalising behaviour; $\mathrm{P}<0.001)$. Table 2 shows data for those who provided information at all data collections in each group compared with those who missed one or more data collection. There was evidence to suggest that those who did not provide information at all data collections were more likely to be male, score poorly on tests of cognitive ability, and score slightly higher on both the depression and anxiety scales. There was evidence to suggest that those lost to follow-up scored slightly higher on the externalising behaviour scale.

Mental health in adulthood-Symptoms of depression and anxiety were more common among those with severe externalising behaviour in adolescence than no externalising behaviour (adjusted odds ratio 1.3, 1.0 to 1.7; table 3). Adolescents with severe externalising behaviour were also more likely to report a history of nervous trouble $(1.5,1.0$ to 2.2$)$. Adolescents with mild externalising behaviour were more likely to be abusing alcohol than those with no externalising behaviour, though this was not the case for those with severe externalising behaviour.
Family life in adulthood-Adolescents with mild or severe externalising behaviour were more likely to become parents during their teenage years (table 4). They were also more likely to get divorced in adulthood compared with those with no externalising behaviour in adolescence and to report that they were unhappy with family life in adulthood. Adolescents with severe externalising behaviour were more likely to report problems in relationships with spouses, children, or friends in adulthood.

Employment and educational outcomes in adulthoodAdolescents with either mild $(2.3,1.9$ to 2.8$)$ or severe (4.0, 2.9 to 5.5$)$ externalising behaviour were more likely to leave school with no qualifications than other adolescents (table 5). They were also more likely to be in manual social classes in adulthood. There were no significant differences between externalising groups with regard to unemployment in adulthood, though adolescents with severe externalising behaviour were more likely to report difficulties with their finances in adulthood (2.1, 1.4 to 3.2).

Global life adversity -The composite measure of global life adversity indicated that adolescents with

Table $3 \mid$ Mental health outcomes in adulthood according to level of externalising behaviour in adolescence (none, mild, severe). Figures are percentage of survey members with adjusted* odds ratios and $95 \%$ confidence intervals

\begin{tabular}{|c|c|c|c|c|c|}
\hline & None & Mild & Severe & Mild $v$ none & Severe $v$ none \\
\hline \multicolumn{6}{|l|}{ Adult depression-anxiety: } \\
\hline No symptoms & 53.1 & 49.7 & 45.1 & \multirow{3}{*}{$1.1(0.9$ to 1.3$)$} & \multirow{3}{*}{$1.3(1.0$ to 1.7$) \dagger$} \\
\hline Mild-moderate symptoms & 43.5 & 45.5 & 47.7 & & \\
\hline Severe symptoms & 3.4 & 4.9 & 7.2 & & \\
\hline \multicolumn{6}{|c|}{ Self reported history of nervous trouble: } \\
\hline Not reported & 78.3 & 74.8 & 71.2 & \multirow{3}{*}{$1.3(1.0$ to 1.6$)$} & \multirow{3}{*}{1.5 (1.0 to 2.2$) \dagger$} \\
\hline Reported once & 15.8 & 16.7 & 19.7 & & \\
\hline Reported twice & 6.0 & 8.5 & 9.1 & & \\
\hline \multicolumn{6}{|l|}{ Alcohol abuse: } \\
\hline No abuse & 89.3 & 85.8 & 86.0 & \multirow{3}{*}{1.4 (1.0 to 1.9$) \dagger$} & \multirow{3}{*}{$1.2(0.7$ to 2.1$)$} \\
\hline Abuse recorded once & 8.4 & 10.4 & 10.6 & & \\
\hline Abuse recorded twice & 2.3 & 3.8 & 3.4 & & \\
\hline
\end{tabular}


Table 4|Family life in adulthood according to level of externalising behaviour in adolescence (none, mild, severe). Figures are percentage of survey members with adjusted* odds ratios and $95 \%$ confidence intervals

\begin{tabular}{|c|c|c|c|c|c|}
\hline & None & Mild & Severe & Mild $v$ none & Severe $v$ none \\
\hline Parenthood before age 20 & 6.8 & 12.5 & 12.3 & 2.3 (1.6 to 3.4$) \ddagger$ & $2.4(1.3$ to 4.4$) \ddagger$ \\
\hline \multicolumn{6}{|l|}{ Marital history: } \\
\hline One marriage (continuing) & 69.6 & 63.0 & 57.5 & - & - \\
\hline One or more divorce(s) & 25.0 & 31.9 & 37.2 & 1.5 (1.2 to 1.9$) \ddagger$ & $1.7(1.2$ to 2.5$) \ddagger$ \\
\hline Never married & 5.5 & 5.2 & 5.3 & 1.0 (0.6 to 1.6$)$ & 0.9 (0.4 to 2.2$)$ \\
\hline Unhappy with family life & 33.5 & 38.6 & 42.8 & 1.3 (1.1 to 1.7$) \ddagger$ & $1.6(1.1$ to 2.2$) \ddagger$ \\
\hline \multicolumn{6}{|l|}{ Problems in relationships with others $\dagger:$} \\
\hline No problems & 53.3 & 49.7 & 41.6 & \multirow{3}{*}{1.1 (0.9 to 1.4$)$} & \multirow{3}{*}{$1.8(1.3$ to 2.5$) \ddagger$} \\
\hline Problems reported once & 31.0 & 33.0 & 35.3 & & \\
\hline Problems reported twice or more & 15.7 & 17.3 & 23.1 & & \\
\hline
\end{tabular}

*Adjusted for sex, father's social class, cognitive ability, and depression/anxiety in adolescence.

†Reported at ages 36,43 , and 53.

$\ddagger$ Significant at $\mathrm{P}<0.05$.

mild externalising behaviour were more likely to experience adversity in adult life than those with no externalising behaviour $(1.9,1.6$ to 2.3$)$. For adolescents with severe externalising behaviour, however, the adjusted odds ratio was 2.9 (2.1 to 4.0 ), with almost three quarters of adolescents with severe externalising behaviour being in the top half of the life adversity scale (table 5).

Sex specific outcomes-Interaction terms between externalising behaviour and sex identified few significant differences between men and women for the relation between externalising behaviour in adolescence and outcomes in adulthood. Women with mild externalising behaviour were more likely to report a history of nervous trouble than women with no externalising behaviour (1.6, 1.2 to 2.2$)$, while there was no such difference among men $(0.9,0.6$ to 1.3 ; interaction term $\mathrm{P}<0.05)$. There were no differences in the relation between externalising behaviour and adult family life outcomes for men and women. There was evidence suggesting that men with severe externalising behaviour were more likely to be in a manual social class $(2.7,1.8$ to 4.0$)$ and to be unemployed $(2.1,1.0$ to $4.4)$ in adulthood; these relations were not apparent for women $(1.2 ; 0.7$ to 2.1 , and $0.5,0.2$ to 1.7 , respectively; both interactions $\mathrm{P}<0.10$ ). Notably, there were no significant interactions between sex and externalising behaviour in adolescence with regard to the global life adversity scale, suggesting that men and women with adolescent externalising behaviour are affected equally in adulthood.

\section{DISCUSSION}

Findings and similar research

In this population based follow-up of 3652 adolescents, those who engaged in externalising behaviour according to their school teachers had a higher likelihood of poor outcomes in numerous domains across a 40 year period. Adolescents who engaged in severe externalising behaviour had poorer mental health, less successful family lives, and poorer social and economic outcomes in adulthood. These poor outcomes also extended to those with milder forms of externalising behaviour. The results remained after adjustment for other

Table $\mathbf{5}$ |Economic, educational, and global adversity outcomes in adulthood according to level of externalising behaviour in adolescence (none, mild, severe). Figures are percentage of survey members with adjusted* odds ratios and $95 \%$ confidence intervals

\begin{tabular}{|c|c|c|c|c|c|}
\hline & None & Mild & Severe & Mild $v$ none & Severe $v$ none \\
\hline No educational qualifications & 30.8 & 52.2 & 65.2 & 2.3 (1.9 to 2.8$) \ddagger$ & $4.0(2.9$ to 5.5$) \ddagger$ \\
\hline Manual social class & 29.7 & 45.6 & 52.0 & 1.7 (1.4 to 2.1$) \ddagger$ & 2.0 (1.5 to 2.8$) \ddagger$ \\
\hline Unemployed at least once & 9.5 & 11.1 & 11.9 & $1.2(0.8$ to 1.8$)$ & $1.2(0.7$ to 2.2$)$ \\
\hline \multicolumn{6}{|l|}{ Financial difficulties†: } \\
\hline No problems & 75.4 & 70.1 & 56.3 & \multirow{3}{*}{1.3 (1.0 to 1.7$)$} & \multirow{3}{*}{$2.1(1.4$ to 3.2$) \ddagger$} \\
\hline Problems reported once & 17.9 & 22.0 & 31.9 & & \\
\hline Problems reported twice or more & 6.8 & 7.8 & 11.8 & & \\
\hline \multicolumn{6}{|l|}{ Global life adversity: } \\
\hline Least adversity & 26.6 & 16.0 & 13.4 & \multirow{4}{*}{1.9 (1.6 to 2.3$) \ddagger$} & \multirow{4}{*}{$2.9(2.1$ to 4.0$) \ddagger$} \\
\hline 2nd quarter & 22.9 & 16.6 & 12.9 & & \\
\hline 3rd quarter & 33.5 & 39.2 & 33.6 & & \\
\hline Most adversity & 17.0 & 28.3 & 40.1 & & \\
\hline
\end{tabular}

*Adjusted for sex, father's social class, cognitive ability, and depression/anxiety in adolescence.

†Reported at ages 36,43 , and 53.

$\ddagger$ Significant at $\mathrm{P}<0.05$. 
important predictors of outcomes in adulthood such as sex, father's social class, adolescent depression and anxiety, and cognitive ability. For every negative outcome we measured, odds ratios were greater than one for adolescents with either mild or severe teacher rated externalising behaviour. Other studies have combined outcomes across several domains to create composite scores to measure life success and have consistently found that those with conduct or externalising problems in adolescence are less likely to be successful as young adults. ${ }^{8-10}$ We created a similar composite score and found that adolescents who engage in either mild or severe externalising behaviour experience multiple impairments that persist throughout adult life.

As in other studies of sex differences in outcomes of adolescent antisocial behaviour, ${ }^{6-18}$ we did not find consistent patterns of sex specific outcomes. There was some evidence to support findings from a New Zealand study in which women with adolescent externalising behaviour were more likely to experience poor mental health as adults and men were more likely to experience economic difficulties, ${ }^{18}$ though, as in the New Zealand study, our findings were not consistent over the range of outcomes measured.

We found that adolescent conduct problems were strongly linked to the presence of symptoms of depression and anxiety in adulthood. Other studies have shown that adolescent conduct disorder commonly occurs with other disorders, including depression, ${ }^{1}$ and predicts depression and anxiety in adulthood. ${ }^{7811-16}$ Furthermore, antisocial behaviour in adulthood is also associated with adult depression and anxiety ${ }^{26}$ Comorbidity in conduct disorder seems to be the rule rather than the exception, ${ }^{3}$ leading some to suggest that the presence of concurrent conduct disorder and depression is less likely to be an example of comorbid disease processes and more likely to be an underlying feature of conduct disorder itself. ${ }^{27}$

Numerous studies have linked conduct problems in adolescence to alcohol abuse in adulthood. ${ }^{8-1114}$ Though we found evidence that adolescents with milder externalising behaviour were more likely to abuse alcohol in adulthood, most adolescents with teacher rated externalising behaviour did not abuse alcohol as adults. A population based cohort study in New Zealand reported that those whose conduct problems did not persist beyond childhood did not have increased rates of alcohol abuse in early adulthood. ${ }^{11}$ Alcohol abuse in adulthood might be more likely only among those with particularly persistent externalising behaviours.

Longitudinal studies that have repeated measures of externalising behaviour have shown that identification of trajectories of such behaviour is important in predicting later life outcomes. ${ }^{8114}$ Antisocial behaviour in early childhood is associated with the formation of delinquent peer groups ${ }^{28}$ and later conduct disorder in adolescence. ${ }^{29}$ In turn, conduct disorder in adolescence is associated with further affiliation with delinquent peer groups and involvement in criminal activities. ${ }^{30}$ Prospective longitudinal studies provide ideal opportunities for better understanding of pathways to and from delinquent behaviour throughout life. ${ }^{31}$ Unfortunately, the national survey does not have repeat data on externalising behaviour beyond what have been presented.

Social and economic problems were much more common in adulthood for adolescents with teacher rated externalising behaviour. Particularly notable was the fact that externalising behaviour was strongly associated with leaving school early. A plausible explanation for the poor socioeconomic outcomes in adulthood is that they are a consequence of limited educational qualifications. A prospective birth cohort from New Zealand, however, has shown that the association between early conduct problems and adverse outcomes in adulthood can be accounted for by the fact that early conduct problems lead to later conduct problems and not that early conduct problems lead to educational underachievement that carries lasting consequences. ${ }^{6}$ Our results support this concept, finding that almost all adult outcomes remained associated with adolescent externalising behaviour after we controlled for educational achievement (data not shown). This suggests that adolescent misconduct might adversely affect developing social behaviours and result in pervasive social and mental health difficulties throughout adult life.

\section{Methodological considerations}

We used data collected almost 50 years ago to identify children who might be diagnosed with a behavioural disorder today. We could not, however, make clinical diagnoses on the basis of the information collected. Dimensionally scored measures of conduct problems are more predictive of future delinquent behaviour than diagnostic categories. ${ }^{7}$ In addition, a study of the future economic impact of antisocial 10 year olds in Britain found that those who had conduct problems that did not reach a diagnostic threshold created a considerable economic burden to society relative to adolescents with no conduct problems. ${ }^{17}$ Similarly, we found that those with milder forms of externalising behaviour also had poor outcomes in adulthood. Consequently, the use of a dimensional scale in the present study might represent a strength rather than a weakness.

The national survey data contain only teachers' assessments of the children's behaviour, with no information from the parents or the children themselves. Teachers can make an important contribution to the identification of adolescent conduct problems, which is often missed when children or parents report on behaviour. ${ }^{1}$ Additionally, teachers' assessments of adolescent conduct problems are more strongly associated with the adolescents' functional impairment than assessments based on information from the parents or the children themselves. ${ }^{32}$ They also predict future delinquent behaviour better than parents' assessments. ${ }^{33}$ Several studies similar to the present study have used data from teachers to measure 


\section{WHAT IS ALREADY KNOWN ON THIS TOPIC}

Clinical and high risk samples suggest that adolescents with severe externalising behaviour or conduct disorder are more likely to be depressed or anxious, abuse alcohol, leave school early, struggle to obtain or maintain employment, and get divorced or separated in adulthood

\section{WHAT THIS STUDY ADDS}

Adolescents in the general population with severe externalising behaviour experience multiple impairments, including poor mental health, relationship difficulties, and economic problems well into adult life

Adolescents with less severe forms of externalising behaviour also experience poor outcomes as adults

externalising behaviour. ${ }^{6-811-1315}$ Teachers' reports of externalising behaviour, however, might differ from what might be captured with different diagnostic tools. Given that our results are similar to those in other samples that used self reports ${ }^{910}$ or reports from parents, ${ }^{6-8111215}$ we think this is unlikely to be the case.

A limitation of this study is the attrition of survey members over the 40 year follow-up period, particularly among those with severe externalising behaviour in adolescence. Our results might be biased because of missing data. Those lost to follow-up were also those with the most extreme difficulties: they were more likely to have lower cognitive ability, to have had depression and anxiety in adolescence, and had more externalising behaviours. Consequently, those lost to follow-up probably had poor outcomes in adulthood, and our results might be conservative estimates of the true picture of outcomes of adolescent externalising behaviour.

Finally, we were unable to differentiate between those whose externalising behaviour began in childhood or in adolescence. People who have childhood onset antisocial behaviour might have more extreme negative outcomes in adulthood. ${ }^{8}$ Consequently, by combining the childhood and adolescent onset groups, our findings might underestimate the severity of poor outcomes for those with the most longstanding externalising behaviours.

Our study, however, also has several methodological strengths. Firstly, the national survey is a population based sample representative of the population of England, Scotland, and Wales born in the years after the second world war. Secondly, the sample is large and allowed for follow-up of 348 adolescents with severe externalising behaviour. Thirdly, because the national survey is one of the oldest prospective cohort studies, it provides follow-up data much further into adult life than other epidemiological studies of adolescent externalising behaviour.

\section{Conclusions}

The results of this prospective population based study suggest that adolescents who engage in externalising behaviour experience multiple social and health impairments that adversely affect them throughout adult life. Given the long term costs to society ${ }^{117}$ and the distressing impact on the adolescents themselves, our results might have considerable implications for public health policy.

Contributors: All authors contributed towards the conception and design of the project, interpretation of the results, and critical review of the manuscript. RAA performed the data analysis. IC designed the data analysis plan, wrote the manuscript, and is guarantor

Funding: This work was supported by the Medical Research Council (BM, $D K)$, National Institute of Health Research (PBJ), Wellcome Trust (PBJ), Stanley Medical Research Institute (PBJ), Sainsbury Centre for Mental Health (RAA), Smith Institute (RAA), British Academy (JM), and the Economic and Social Research Council (JM; grant number RES-000-222311). TJC is funded by a public health career scientist award from the UK Department of Health. IC is supported by a population health investigator award from the Alberta Heritage Foundation for Medical Research.

Competing interests: None declared

Ethical approval: The National Survey of Health and Development has received ethical approval from the Central Manchester local research ethics committee.

Provenance and peer review: Not commissioned; externally peer reviewed.

1 Ford T, Goodman R, Meltzer H. The British child and adolescent mental health survey 1999: the prevalence of DSM-IV disorders. J Am Acad Child Adolesc Psychiatry 2003;42:1203-11.

2 Costello EJ, Angold A, Burns BJ, Stangl DK, Tweed DL, Erkanli A, et al. The Great Smoky Mountains study of youth. Goals, design, methods, and the prevalence of DSM-III-R disorders. Arch Gen Psychiatry 1996;53:1129-36.

3 Lambert EW, Wahler RG, Andrade AR, Bickman L. Looking for the disorder in conduct disorder. J Abnorm Psychol 2001;110:110-23.

4 Collishaw S, Maughan B, Goodman R, Pickles A. Time trends in adolescent mental health. I Child Psychol Psychiatry 2004;45:1350-62

5 Robins LN. Deviant children grown up: a sociological and psychiatric study of a sociopathic personality. Baltimore: William \& Wilkins, 1966.

6 Fergusson DM, Horwood LJ. Early conduct problems and later life opportunities. / Child Psychol Psychiatry 1998;39:1097-108.

7 Fergusson DM, Horwood LJ, Ridder EM. Show me the child at seven: the consequences of conduct problems in childhood for psychosocial functioning in adulthood. J Child Psychol Psychiatry 2005;46:837-49.

8 Moffitt TE, Caspi A, Harrington H, Milne BJ. Males on the life-coursepersistent and adolescence-limited antisocial pathways: follow-up at age 26 years. Dev Psychopathol 2002;14:179-207.

9 Farrington DP. Later adult life outcomes of offenders and nonoffenders. In: Brambring M, Lösel F, Skowronek H, eds. Children at risk: assessment, longitudinal research, and intervention. Berlin: Walter de Gruyter, 1989:220-44.

10 Farrington DP, Coid JW, Harnett LM, Jolliffe D, Soteriou N, Turner RE, et al. Criminal careers up to age 50 and life success up to age 48: new findings from the Cambridge study in delinquent development. London: Home Office Research, Development and Statistics Directorate, 2006.

11 Odgers CL, Caspi A, Broadbent JM, Dickson N, Hancox RJ, Harrington $\mathrm{H}$, et al. Prediction of differential adult health burden by conduct problem subtypes in males. Arch Gen Psychiatry 2007;64:476-84.

12 Sourander A, Multimaki P, Nikolakaros G, Haavisto A, Ristkari T, Helenius $\mathrm{H}$, et al. Childhood predictors of psychiatric disorders among boys: a prospective community-based follow-up study from age 8 years to early adulthood. I Am Acad Child Adolesc Psychiatry 2005;44:756-67.

13 Kratzer L, Hodgins S. Adult outcomes of child conduct problems: a cohort study. J Abnorm Child Psychol 1997;25:65-81.

14 Wiesner M, Kim HK, Capaldi DM. Developmental trajectories of offending: validation and prediction to young adult alcohol use, drug use, and depressive symptoms. Dev Psychopathol 2005;17:251-70.

15 Fergusson DM. Conduct problems in childhood and psychosocia outcomes in young adulthood: a prospective study. J Emot Behav Disord 1998;6:2-18.

16 Kim-Cohen J, Caspi A, Moffitt TE, Harrington H, Milne BJ, Poulton R. Prior juvenile diagnoses in adults with mental disorder: developmental follow-back of a prospective-longitudinal cohort. Arch Gen Psychiatry 2003;60:709-17.

17 Scott S, Knapp M, Henderson J, Maughan B. Financial cost of social exclusion: follow up study of antisocial children into adulthood. $B M J$ 2001;323:191.

18 Moffitt TE, Caspi A, Rutter M, Silva PA. Sex differences in antisocial behaviour: conduct disorder, delinquency, and violence in the Dunedin longitudinal study. Cambridge: Cambridge University Press, 2001. 
19 Wadsworth ME, Butterworth SL, Hardy RJ, Kuh DJ, Richards M, Langenberg C, et al. The life course prospective design: an example of benefits and problems associated with study longevity. Soc Sci Med 2003;57:2193-205.

20 Rodgers B. Behaviour and personality in childhood as predictors of adult psychiatric disorder. J Child Psychol Psychiatry 1990;31:393-414.

21 Colman I, Ploubidis GB, Wadsworth ME, Jones PB, Croudace TJ. A longitudinal typology of symptoms of depression and anxiety over the life course. Biol Psychiatry 2007;62:1265-71.

22 Ewing JA. Detecting alcoholism. The CAGE questionnaire. JAMA 1984;252:1905-7.

23 Kuh D, Bassey EJ, Butterworth S, Hardy R, Wadsworth ME. Grip strength, postural control, and functional leg power in a representative cohort of British men and women: associations with physical activity, health status, and socioeconomic conditions. J Gerontol A Biol Sci Med Sci 2005;60:224-31.

24 Richards M, Hardy R, Kuh D, Wadsworth ME. Birth weight and cognitive function in the British 1946 birth cohort: longitudinal population based study. BMJ 2001;322:199-203.

25 Colman I, Wadsworth ME, Croudace TJ, Jones PB. Forty-year psychiatric outcomes following assessment for internalizing disorde in adolescence. Am J Psychiatry 2007;164:126-33.
26 Nock MK, Kazdin AE, Hiripi E, Kessler RC. Prevalence, subtypes, and correlates of DSM-IV conduct disorder in the National Comorbidity Survey Replication. Psychol Med 2006;36:699-710.

27 Angold A, Costello EJ, Erkanli A. Comorbidity. J Child Psychol Psychiatry 1999;40:57-87.

28 Lacourse E, Nagin DS, Vitaro F, Cote S, Arseneault L, Tremblay RE. Prediction of early-onset deviant peer group affiliation: a 12-year longitudinal study. Arch Gen Psychiatry 2006;63:562-8.

29 Cote S, Tremblay RE, Nagin DS, Zoccolillo M, Vitaro F. Childhood behavioral profiles leading to adolescent conduct disorder: risk trajectories for boys and girls. J Am Acad Child Adolesc Psychiatry 2002;41:1086-94.

30 Simonoff E, Elander J, Holmshaw J, Pickles A, Murray R, Rutter M. Predictors of antisocial personality. Continuities from childhood to adult life. BrJ Psychiatry 2004;184:118-27.

31 Colman I, Jones PB. Birth cohort studies in psychiatry: beginning at the beginning. Psychol Med 2004;34:1375-83.

32 Hart EL, Lahey BB, Loeber R, Hanson KS. Criterion validity of informants in the diagnosis of disruptive behavior disorders in children: a preliminary study. J Consult Clin Psychol 1994;62:410-4.

33 Bank L, Duncan T, Patterson GR, Reid J. Parent and teacher ratings in the assessment and prediction of antisocial and delinquent behaviors. J Pers 1993;61:693-709.

Accepted: 5 October 2008 